Annette Kamp

Klaus T. Nielsen ${ }^{1}$

${ }^{1}$ Centre for Working Environment \&

Working Life. Department of

Environmental, Social and Spatial

Change. Roskilde University. Denmark

*Tradução: José Marçal jackson

Revisão Técnica da tradução: Thais Helena de Carvalho Barreira e José Marçal Jackson Filho

*** Trabalho apresentado no $16^{\circ}$ Congresso Mundial da Associação Internacional de Ergonomia (IEA), Maastricht, Holanda - 9a 15 de julho de 2006.

Contato:

Klaus T. Nielsen

E-mail:

ktn@ruc.dk

\section{Regulação em Rede do Ambiente de Trabalho*}

\author{
Network Regulation of the Working Environment**
}

\section{Resumo}

Este artigo trata do conceito de governança em rede como contraponto à compreensão do processo convencional, hierarquizado, de regulação no campo do ambiente de trabalho. A forma como as redes podem estimular mudanças na regulação do ambiente de trabalho é estudada em dois casos na Dinamarca. O primeiro caso se refere à alta incidência de distúrbios músculo-esqueléticos - na atividade de manuseio de pacientes - encontrados no setor saúde. A rede, desenvolvida de baixo para cima, gerou uma conexão do problema a novas soluções, em particular, com a criação de um novo agente social, o "instrutor de transferência", a partir da idéia de que "pessoas são transferidas, não levantadas como pesos'. O segundo caso trata de um esforço para integrar a promoção da saúde com a forma de se pensar saúde no trabalho, a fim de enfrentar a desigualdade social em saúde. Iniciada de cima para baixo, a rede não conseguiu se estabilizar nem promover com êxito a abordagem integrada da promoção da saúde no local de trabalho. Os dois casos apontam, todavia, para a importância da aproximação de diversos grupos profissionais, quando os esforços pretendem ser verdadeiramente, inovadores e bem sucedidos. Em contraste com as visões que celebram a ausência do Estado, discuti-se também a importância deste como meta-governante nos processos que visam revigorar a regulação.

Palavras-chave: governança em rede, ambiente de trabalho, cuidadores no setor saúde, promoção da saúde no local de trabalho.

\begin{abstract}
This article discusses the concept of network governance as a supplement to the conventional understanding of regulation in the field of working environment. How networks can stimulate change in working environment regulation is studied in two cases in Denmark. The first case concerns the problem with musculoskeletal strains in the care sector - manual handling of people. In Denmark a network has grown from below, and this network has generated a storyline that connects the problem with new solutions, in particular the creation of the 'transfer instructor''we transfer people, we don't lift'. The second case deals with an effort to integrate health promotion with occupational health thinking; two fields (public health and OHS) that for years have been separated in a Danish context. The problem in this case was/is a profound social inequality in health. This network was initiated from above, and has so far not managed to stabilize a network that is able to successfully promote the integrate approach of workplace health promotion. Both cases point at the importance of bridging gaps between various professional groups if the efforts are to be truly innovative and successful. And they point at the importance of the state as a meta-governor in processes that aim at invigorating the regulation; the concept of network governance can be taken to celebrate the absence of the state; our cases don't.
\end{abstract}

Keywords: Network governance, working environment, the care sector, workplace health promotion. 


\section{Introdução}

\section{Novos desafios para a regulação do ambiente de trabalho}

Em anos recentes, o ambiente de trabalho em países como a Dinamarca mudou profundamente. Dois fatores importantes nesse desenvolvimento são o crescimento do setor econômico de prestação de serviços e a introdução de novas formas de organização e de gestão do trabalho. Portanto, problemas ergonômicos e psicossociais se tornam cada vez mais importantes, enquanto problemas tradicionais, como a presença de substâncias químicas e de ruído, recuam para um segundo plano. A conseqüência desse desenvolvimento é uma crescente complexidade, tanto em termos dos problemas como das condições para resolvê-los. Assim, existe um constante desafio na delimitação do campo político da Saúde e Segurança no Trabalho em relação a outros campos, tais como o do emprego e o da saúde (JAMES, 2003).

Tendências sociais, em geral, influenciam os conceitos de saúde e segurança no trabalho e os meios para melhorá-los também. O descrédito generalizado nas normas regulamentadoras e nas autoridades como sendo o melhor caminho para a regulação de assuntos sociais como a saúde e a segurança no trabalho e o esperado empoderamento de empregados para o auto-cuidado são exemplos de tais tendências, o que constitui condições políticas gerais para a melhoria da saúde no trabalho.

Para a maior parte das leis relativas à Saúde e Segurança no Trabalho (SST) implementadas na década de 1970, nos países ocidentais, presume-se que a regulação está sujeita a mudanças, de modo a acompanhar os desenvolvimentos sociais e tecnológicos (como pode ser verificado na lei dinamarquesa ${ }^{2}$. A legislação inclui componentes de regulação reflexiva como estratégia para assegurar sua implementação e assume-se que os agentes sociais do mercado de trabalho, empregadores e trabalhadores, desempenhem papel preponderante no estabelecimento da dinâmica de mudanças (FRICK; WREN, 2000). Uma das fragilidades desse modelo é que o campo parece tornar-se míope e, dessa forma, incapaz de lidar com os desafios da sua delimitação. A outra fragilidade é que a dinâmica social entre os agentes sociais dos dois lados tende a endurecer-se em papéis fixos, de modo que diminui a habilidade em pensar alternativas. A questão é como recriar dinâmicas que possam resultar em mudanças e avanços no campo da SST.
Neste artigo, defendemos a idéia de que a 'governança em rede' pode desempenhar importante papel de renovação no processo de regulação relativa à "SST" e enfatizamos de que modo a governança em rede pode agir como um veículo para a inovação. Caracteristicamente, as redes não estão sujeitas às mesmas tensões institucionais que as instituições políticas tradicionais. Elas são tipicamente heterogêneas, pois incluem atores de esferas sociais diferentes (Estado, mercado, sociedade civil) ou de diferentes níveis da hierarquia. Apresentamos neste trabalho dois casos que ilustram o papel da governança em rede na renovação do campo da "SST". Além disso, exploramos o processo de estabelecimento desses tipos de redes a fim de analisar sob quais condições elas podem ser bem sucedidas.

\section{Governança em Rede - um modelo estrutural teórico}

No campo da Ciência Política, tem havido crescente interesse pela governança em rede (ver, por exemplo, RHODES, 2000). Uma razão óbvia para isso, é que esses tipos de participação plural para a regulação estão se espalhando rapidamente nas sociedades ocidentais. Mas, outra razão, é que a governança representa uma espécie de terceiro caminho, que não se baseia puramente no mercado nem no Estado, mas que combina elementos de ambos e ainda inclui a sociedade civil.

Bob Jessop ${ }^{3}$ (2006) define governança como um caminho interativo de governar, que não é hierárquico como a regulação pública clássica, nem anárquico como a regulação de mercado. Caracteristicamente, atores pertencentes a diferentes campos e níveis contribuem para a regulação através de cooperação e de deliberação.

A governança em rede parece ser um meio promissor para abordar problemas complexos. Em geral, admite-se que a governança em rede - quando está funcionando bem - possui diversas vantagens em comparação com o exercício da governança tradicional: as soluções são melhores porque são ajustadas ao contexto específico, mais pró-ativas e implementadas mais facilmente. A facilidade da implementação se deve ao fato dos atores sociais com poder de decisão ${ }^{4}$ fazerem parte da rede, dos conflitos entre os diferentes atores serem resolvidos diante de todos ("sem nada a esconder") e de uma autoria conjunta de soluções estar disponível.

As governanças em rede são compreendidas, aqui (ver, por exemplo, SØrensen; Torfing, 2005),

\footnotetext{
${ }^{2}$ Objetivo da Lei Dinamarquesa que rege o Ambiente de Trabalho ('Danish Working Environment Act'): “...um ambiente de trabalho seguro e saudável que deve, a qualquer momento, estar de acordo com o desenvolvimento social e técnico da sociedade...".

${ }^{3}$ Sociólogo britânico, figura proeminente no seio desses debates.

${ }^{4}$ Nota do tradutor: no original 'stakeholders'.
} 
como uma inter-relação relativamente estável entre instituições:

$$
\begin{aligned}
& \text { - Operacionalmente autônomas; } \\
& \text { - Que interagem e se influenciam mutuamente atra- } \\
& \text { vés de negociações; } \\
& \text { - Que se auto-regulam - dentro dos limites freqüen- } \\
& \text { temente estabelecidos pelas autoridades públicas; } \\
& \text { - Que contribuem em sentido amplo para o governo } \\
& \text { estabelecido publicamente. }
\end{aligned}
$$

A rede metafórica dirige nossa atenção para a transformação do Estado em um centro para o governo político. Mas, ao mesmo tempo, as teorias acerca da governança em rede também dão origem a novos entendimentos para o processo de formulação de política ${ }^{5}$. Tradicionalmente o processo de formulação de política está concebido como um processo racional em conformidade com princípios técnico-burocráticos. Essa concepção tem sido objeto de uma crítica antiga. Conceitos como o da "racionalidade limitada" ${ }^{6}$ " (MARCH; SIMON, 1958), muddling through ${ }^{7}$ (LINDBLOM, 1959), e o "modelo de lata de lixo ${ }^{8}$ (MARCH; OLSEN, 1976) oferecem perspectivas que são alternativas melhores para a compreensão das complexidades do processo de formulação de política.

Mas, enquanto essas abordagens justificam os desvios a partir do modelo racional como tentativas para explicar as falhas de governança e os problemas relacionados ao alinhamento do processo de formulação de política, a abordagem da governança em redes contempla as características não hierárquicas e policêntricas do processo de regulação como potencialmente produtivas. A formulação de políticas, conforme essa abordagem reivindica, não é somente desenvolvida centralmente, mas em negociações locais entre insti- tuições dentro de uma rede e, também, muitos estudos de governança em rede estão focalizados no desenvolvimento local da formulação de políticas. Outro ponto importante é que metas e visões são criadas e revisadas ao longo do mesmo processo pelo qual se supõe que sejam implementadas. Desse modo, o processo de formulação de políticas e o processo de implementação estão intimamente entrelaçados (KICKERT; KLIJN; KOPPENJAN, 1997).

Nos últimos anos, redes de instituições tornaramse um campo de pesquisa dentro de diversas disciplinas: Sociologia, Ciência Política, bem como Teoria da Organização. Conseqüentemente, foram desenvolvidas diferentes abordagens teóricas para a governança em rede.

Neste artigo, usamos uma abordagem neo-institucionalista (SCOTT, 1994). As redes são consideradas como instituições, caracterizadas por concepções, normas e valores compartilhados e relacionados, por exemplo, com os problemas em questão, como eles são resolvidos, e por quem. Os atores - e aqui nos referimos a atores coletivos - na rede desenvolvem e compartilham concepções e, por participarem da rede, eles próprios também sofrem mudanças; eles adquirem novas habilidades políticas e identidades (MARCH; OLSEN, 1995), No processo de construir redes e novos conceitos, e de estabilizá-los, o estabelecimento de um storyline é essencial, de acordo com o cientista político holandês Maarten Hajer (HAJER, 1995 e HAJER; WAGENAAR, 2003). Um storyline é uma narrativa curta, condensada, com qualidades metafóricas, que permite a formação de ampla coalizão de atores - uma rede - e que dá suporte à ampliação e à posterior institucionalização da rede.

\footnotetext{
${ }^{5}$ Nota do tradutor: no original policy process.

${ }^{6}$ Nota do tradutor: O conceito bounded rationality é traduzido em português de duas formas: “racionalidade constrangida” (SILVA, P.L.B.; MELO, M.A.B. O processo de implementação de políticas públicas no Brasil: características e determinantes da avaliação de programas e projetos. NEPP/ UNICAMP, Textos para Discussão, n. 48, 2000. Disponível em < http://www.nepp.unicamp.br>. Acesso em: 13 maio 2009$)$ e “racionalidade limitada” (SOUZA, C. Políticas Públicas: uma revisão da literatura. Sociologias, Porto Alegre, v. 8, n. 16, p. 20-45, jul./dez. 2006). Esse conceito é utilizado para designar as limitações cognitivas e contingenciais dos formuladores de políticas, dos tomadores de decisão públicos (policy makers). Tais limitações são apresentadas por dois aspectos distintos: 1) em decorrência de problemas diversos, como informação incompleta ou imperfeita, constrangimento de tempo para a tomada de decisão, auto-interesse dos tomadores de decisão etc. (SOUZA, 2006); 2) como limitações decorrentes da própria complexidade dos fenômenos sociais com os quais se está lidando e das próprias limitações do conhecimento das disciplinas sociais sobre a sociedade: "os formuladores de política não podem controlar, nem muito menos prever as contingências do policy environment no futuro” (SILVA; MELO, 2000; p.9).

${ }^{7}$ Nota do tradutor: Lindblom (1959) demonstra em sua abordagem do Muddling Through que o processo de formulação e decisão por determinadas políticas ocorre de forma incremental (visão gradualista): na formulação de novas políticas, acrescentam-se pequenas mudanças a políticas e informações já existentes; esse processo acarreta mudanças políticas que são mais evolucionárias do que revolucionárias. O termo muddling through ressalta que alcançam-se os objetivos propostos de forma confusa, desnorteada, porque, segundo Lindblom, os formuladores não estão atentos às teorias políticas para fundamentar o que estão fazendo: suas decisões baseiam-se em experiências passadas e testam-se na prática.

${ }^{8}$ Nota do tradutor: O modelo garbage can ou "lata de lixo" foi sugerido para ilustrar um comportamento organizacional em que existe um acoplamento fraco entre problemas e soluções disponíveis, mas no qual a questão temporal é crucial. As soluções ou políticas são escolhidas dentre alternativas disponíveis numa "lata de lixo" porque não são soluções novas e pensadas para aquela situação. Elas estão disponíveis naquele dado momento e são escolhidas pelos tomadores de decisão (policy makers) em função de sua simultaneidade com os problemas a serem tratados (MARCH, J.G.; OLSEN, J.P. Neo-institucionalismo: fatores organizacionais na vida política. Revista de Sociologia e Política, Curitiba, v. 16, n. 31, p. 121-142, nov. 2008).
} 
Nos estudos de caso a seguir apresentados, analisamos o estabelecimento de duas redes de governança no campo da SST. Primeiro, nós identificamos o storyline produzido pela rede, analisamos as concepções que delineiam os problemas que a rede englobará e as soluções que parecem adequadas para os atores. Em seguida, passamos pelos diferentes atores, que estão incluídos na rede e olhamos suas diferentes interpretações do storyline e suas contribuições na construção da rede. Eventualmente, nós identificamos diferentes recursos que tornam possível o estabelecimento da rede e a expansão e institucionalização do novo storyline: arenas onde os atores podem interagir, desenvolver habilidades e conhecimentos profissionais e construir instituições formais, regras e regulamentos.

Os estudos de casos estão baseados numa série de entrevistas com pessoas envolvidas nas redes em questão e em material escrito - mais ou menos público - que vieram a nosso encontro no processo de entrevistar as pessoas. Em cada estudo de caso, a análise, que em linhas gerais segue os passos mencionados acima, foi documentada num relatório e apresentada num seminário para um grupo representativo de 12 a 15 pessoas ativas na rede - seus comentários foram incorporados na análise.

\section{Estudos de caso}

\section{Caso 1. Cuidadores: ambiente de trabalho no setor de Saúde}

\section{Contextualização}

No final da década de 1980, a aposentadoria precoce apresentava-se como um enorme problema entre enfermeiros, auxiliares de enfermagem e trabalhadores sociais no setor público de saúde. Esses grupos desempenham o trabalho de cuidadores em home care (atendimento residencial), casas de repouso, hospitais, escolas infantis e instituições especializadas para pessoas com incapacidades físicas e mentais. Para ilustrar a extensão do problema, em 1991, a companhia de seguros que cobria os auxiliares de enfermagem - "PenSam" - concluiu que eles tinham que reduzir as pensões normais em $25 \%$ devido aos custos da aposentadoria precoce. A análise dos dados revelou que as lesões lombares constituíam a principal causa da aposentadoria precoce ${ }^{9}$. Assim, o esforço músculoesquelético no trabalho dos cuidadores surgiu como o problema central.

Este estudo de caso mostra como uma rede que cresceu a partir de sua base desenvolveu novo storyline, criando novo conceito para a governança, de forma a englobar a complexidade do problema e a transgredir os limites de uma concepção muito estreita do ambiente de trabalho. O estudo de caso está baseado em nove entrevistas semi-estruturadas, qualitativas, com pessoas-chaves de diferentes instituições da rede, e análise de uma abrangente quantidade de material escrito, compreendendo: planos de ação, material de campanha, relatórios de avaliação, relatórios de pesquisas, artigos em mídias profissionais como no periódico Danish Physiotherapists, entre outros.

\section{Desafios para a regulação tradicional}

Os distúrbios músculo-esqueléticos constituíam um grande desafio para a regulação em SST na época (e ainda constituem). Enquanto riscos tradicionais como ruído, poeiras e substâncias químicas podem ser descritos através de simples modelos dose-resposta, formando a base da regulação convencional (normas, fiscalização e controle), os problemas ergonômicos são freqüentemente de maior complexidade. No início da década de 1990, autoridades dos países nórdicos fizeram um esforço conjunto para enfrentar esse problema, compilando modelos para a avaliação de exposição e para a fiscalização (ANDERSEN; BJURVALD, 1994, 1997). Contudo, esses modelos visavam fundamentalmente atividades de manuseio de materiais em estabelecimentos industriais.

Dessa forma, a regulação não obteve êxito em reduzir os problemas ergonômicos no trabalho de cuidadores no setor saúde, sobretudo por não levar em conta o caráter relacional do trabalho, além de não considerar fatores culturais e organizacionais. Localmente, as maiores instituições estabeleceram programas de treinamento para seus funcionários, abordando técnicas de levantamento de cargas, a fim de prevenir dores e lesões na coluna lombar. A experiência, entretanto, mostrou que esse tipo de treinamento ficou muito aquém de apresentar resultados efetivos.

\section{Um novo storyline - do levantamento de pesos para a suave transferência}

Na década seguinte, um novo story-line foi estabelecido. A curta mensagem que esse storyline comunica é que o pesado manuseio de pessoas deveria ser substituído pela transferência cuidadosa.

Essa concepção de transferência está baseada em dois pilares:

- Oferecer cuidados e atenção constitui-se no ponto crucial da identidade profissional de um cuidador. Portanto, se o ato de cuidar e adotar medidas para proteger o cuidador contra esforços exagerados são compreendidos como conflitantes, a prioridade estará sempre colocada no ato de cuidar. O novo storyline encara a transferência e o levantamento de clientes como um processo ativo que 
envolve tanto o cuidador quanto o cliente, focalizando na relação entre os dois. A filosofia é que, quando o cliente está envolvido na transferência, ele amplia seu poder física e mentalmente. Técnicas e auxílios técnicos são desenvolvidos para apoiar essa concepção.

- O problema é sócio-técnico e, conseqüentemente, as soluções não podem limitar-se à situação de trabalho. Para tratar de problemas multidimensionais, os "instrutores de transferência" locais também necessitam ser treinados como "agentes de mudança". Os "instrutores de transferência" devem facilitar mudanças em diversos níveis - rotinas, organização e cultura de trabalho - e os necessários processos de mudança devem geralmente ser formulados em termos de aprendizado organizacional.

Assim, o conceito dominante para a prevenção nesse campo se desenvolve como uma questão de educar os "agentes de transferência" locais tanto para uma abordagem ergonômica mais abrangente como para serem agentes de mudanças organizacionais. Em 2004, 80\% de todas as municipalidades dinamarquesas foram cobertas por um sistema de "instrutores de transferência” (SWEC, 2004). Cursos padronizados de treinamento para os instrutores foram desenvolvidos, seminários anuais para os instrutores foram realizados em todo o país e, em alguns locais de trabalho, eles também receberam um bônus salarial especial. Assim, essa abordagem está, de fato, largamente institucionalizada.

Esse storyline é desenvolvido por - e se torna a estrutura compartilhada por - uma rede de instituições públicas, quase-públicas e privadas. As autoridades - como a inspetoria do trabalho - estão incluídas, apenas, de forma tênue na rede.

\section{A construção da rede e das políticas}

\section{A parte estratégica da rede}

O Conselho Setorial do Ambiente de Trabalho ${ }^{10}$ (CSAT) é uma das entidades centrais na rede ${ }^{11}$. O CSAT é um comitê consultivo, cujas atividades estão baseadas na cooperação entre os participantes do mercado de trabalho do setor saúde. Os problemas de SST no setor saúde são um caso em que as discordâncias entre os agentes sociais em nível central parecem paralisar a ação. A solução encontrada pelo CSAT foi, portanto, de- monstrar concordância e vigor político conjunto para criar foco político e para dar prioridade à prevenção da dor lombar nos locais de trabalho (SOCIOLOGISK ANALYSE, 2000).

Conseqüentemente, em 1995, as partes estabeleceram o "Plano de Ação para o Manuseio de Pessoas". A meta explícita era reduzir o número de lesões à metade em 5 anos. Os sindicatos foram particularmente ativos em implantar o plano, enquanto que as organizações patronais foram mais relutantes (SOCIOLOGISK ANALYSE, 2000).

Alguns dos meios aqui usados assemelham-se àqueles utilizados em campanhas tradicionais: seminários, panfletos, teatro, vídeos etc. Mas, assistiu-se a uma importante inovação no trabalho do conselho. Percebendo que o CSAT por si próprio era incapaz de resolver esse grande problema social, o conselho concluiu que deveria "empurrar a bola de neve", tentando envolver e engajar outros atores. O CSAT considerouse como um construtor de rede (KORREMANN, 1999). A cooperação com os recém-estabelecidos Serviços de Segurança e Saúde no Trabalho para os setores sociais e de saúde é colocada em prática imediatamente. Mas o CSAT tenta também envolver entidades em outros níveis, como o Ministério da Saúde e o Ministério do Trabalho. Uma das agendas do CSAT é que um importante programa de pesquisa deveria ser criado, uma vez que a pesquisa nessa área é escassa, embora extremamente necessária. De fato, o CSAT obtém êxito ao estabelecer financiamento público para pesquisa teórica e relacionada com a prática no que diz respeito ao manuseio de pessoas (KORREMANN, 1999 e SOCIOLOGISK ANALYSE, 2000). Os projetos de pesquisa resultantes, que se constituíram em oportunidade e meios para a construção da rede, envolveram muitos atores: instituições de pesquisas, Serviços de SST desses setores, a importante companhia de seguros "Pen-Sam", firmas de tecnologia etc. Vários dentre os projetos, relacionados com a prática de fato, testaram modelos de soluções envolvendo o uso de "instrutores de transferência” (ESKELINEN; HANSEN, 2004).

O CSAT enxergou a si próprio como um elo de ligação para essas atividades. Os resultados dos projetos-pilotos foram resumidos, comparados e comunicados ao setor saúde. No ano de 2000, uma rede de "instrutores de transferência" locais foi estabelecida e seminários anuais com cerca de 300 participantes têm sido realizados desde então.

\footnotetext{
${ }^{10}$ Nota do tradutor: os termos em inglês que os autores utilizam ao longo do texto constituem uma tradução livre dos termos dinamarqueses reais para a versão em inglês do texto, que ora estamos vertendo para o português. No texto 'Sector Working Environment Council' - CSAT. Utilizaremos doravante a sigla em português CSAT.

${ }^{11} \mathrm{O}$ conselho setorial do ambiente de trabalho, 'CSAT', está estabelecido como parte da Lei relativa ao Ambiente de Trabalho ('Work Environment Act'), com a finalidade de ajudar empresas privadas dentro do setor para resolver questões ambientais. O mercado de trabalho dinamarquês está dividido em 11 setores, cada um deles coberto por seu próprio conselho. Suas atividades consistem em: preparar informações e orientações setoriais, identificar os problemas especiais do ambiente de trabalho no setor, contribuir para a preparação de documentação e desenvolver e implementar atividades de treinamento.
} 


\section{A parte profissional da rede}

O conceito de "instrutores de transferência" foi principalmente desenvolvido nos Serviços de Saúde e Segurança no Trabalho. Ele representa a fusão de duas linhas de pensamento: uma (proeminente entre profissionais do ambiente de trabalho), que pensa como o ambiente de trabalho deve ser melhorado, e outra (proeminente entre profissionais de saúde), que mantém seu foco de trabalho sobre o cuidado ao cliente.

Nos anos 1990, os Serviços de SST dinamarqueses estavam preocupados em como capacitar e dar poderes à 'organização de segurança do local de trabalho' para cuidar do ambiente de trabalho e em como criar consciência e aprendizado na organização em relação a problemas do ambiente de trabalho. Assim, os profissionais desses Serviços de SST se vêem como consultores de processos promovendo aprendizagem e mudança organizacional (LIMBORG, 2001). O envolvimento de empregados no âmbito do "chão de fábrica" é parte necessária de tal estratégia.

A partir de 1994, as municipalidades, e junto com elas uma grande parte do setor público de saúde, foram cobertas pelos Serviços de SST. Conseqüentemente, os Serviços de SST expandiram-se. Considerando os grandes problemas ergonômicos no setor, principalmente fisioterapeutas e terapeutas ocupacionais foram empregados. Muitos deles vieram de empregos no setor de cuidados à saúde. Eles foram inspirados por diferentes "escolas" ou paradigmas relacionados com a transferência de pessoas. Os paradigmas dominantes (ver, por exemplo, LUNDE, 2001) defendem a idéia de que se deveria parar de pensar nessa tarefa como um levantamento de um peso passivo, ou transferência de uma carga, e focalizar-se na relação, utilizando-se os recursos do paciente.

A maioria dos terapeutas nos maiores Serviços de SST combinam esses dois tipos de compreensão. Eles desenvolvem cursos de treinamento para instrutores como sua principal atividade. A ênfase desses cursos não está somente relacionada a técnicas de transferência, embora essa seja uma parte importante deles. O conceito que é ensinado é, de certa forma, uma nova filosofia, que é sustentada por diferentes técnicas, de modo que o foco recai também sobre mudanças nas culturas organizacional e profissional.

\section{Institutos de Pesquisa}

Dois tipos de instituições de pesquisa são incluídos nessa ação. Primeiro, as clínicas regionais de Medicina Ocupacional, que recebem cuidadores lesionados como pacientes e, segundo, o Instituto Nacio- nal de Saúde Ocupacional. A abordagem da pesquisa foi principalmente médica ou fisiológica. Até a metade da década de 1990, os distúrbios músculo-esqueléticos constituíam um campo de pesquisa de baixo prestígio e pouquíssima pesquisa foi realmente realizada. Contudo, a grande atenção dada ao problema e às possibilidades de financiamento para essas pesquisas realmente promoveram novo interesse.

Na visão dessas instituições, os problemas ergonômicos constituíam um problema de pesquisa: Por que o trabalho no setor de atendimento público da saúde produz tantos danos físicos, quando a carga de trabalho comparada com o trabalho na indústria é, de certa forma, menor? (DONBÆK; SCHIBYE, 1998). Mas, essa abordagem relativamente estreita é logo posta de lado para ser substituída por um foco mais amplo sobre as possibilidades de mudanças. Uma corrente de pesquisa tentou demonstrar através de experimentos biomecânicos que as novas técnicas que se apóiam sobre a cooperação cliente-cuidador, realmente conduziram à redução dos agravos por esforço. Outra corrente partiu do conceito contemporâneo para a prevenção, denominado programas de treinamento para instrutores, e tentou documentar o efeito desse programa em termos da redução no número de incidentes de lombalgias.

A pesquisa desempenhou um importante papel na consolidação do conceito e propiciou que os pesquisadores fossem amplamente divulgados como especialistas na mídia profissional e cooperassem com os Serviços de SST e com o CSAT em numerosos projetos.

\section{As organizações privadas na rede.}

Organizações privadas também foram incluídas na rede. O fundo de pensão 'Pen-Sam' foi envolvido já em meados dos anos 1990. Para o fundo "Pen-Sam, as lesões e as aposentadorias precoces impuseram um sério problema econômico, que o motivou fortemente a agir. Primeiro, o Pen-Sam subsidiou amplas iniciativas, tais como as pesquisas. Financiaram, por exemplo, uma análise de custo-benefício que demonstrou aos políticos como essas lesões eram dispendiosas para a sociedade. Em segundo lugar, levaram adiante diferentes campanhas a fim de impactar seus clientes para comportar-se de maneira segura. Mas também mantiveram uma política geral de compartilhamento de conhecimentos, envolvendo-se na maioria das atividades no campo como: reuniões, seminários, grupos de apoio.

Firmas de tecnologia desempenharam um papel na redetambém. Osetor da indústria dinamarquesa que produz tecnologia para pessoas com necessidades especiais é um dos maiores e dos mais inovadores da Europa ${ }^{12}$.

\footnotetext{
${ }^{12}$ A Lei Social dinamarquesa estabelece - em termos amplos - que uma pessoa com necessidades especiais tem direito à assistência técnica, de modo que ela/ele possa manter o mesmo padrão de condições de vida de outros cidadãos. Esse é um dos fatores que criaram um ambiente vantajoso para esse setor industrial na Dinamarca.
} 
O foco de desenvolvimento de tecnologia nesse setor industrial tem sido os clientes, suas características e necessidades, e o ambiente físico onde convivem. Nos anos 1990, contudo, a atenção foi dirigida para os cuidadores e para o emprego da tecnologia a fim de reduzir seus esforços físicos e prevenir lesões. Conseqüentemente, a tecnologia empregada para pessoas com necessidades especiais foi vista como tecnologia para a melhoria do ambiente de trabalho. Mais do que isto, desenvolveuse tecnologia baseada nos princípios de transferência como um processo de cooperação entre o cliente e o cuidador. As maiores firmas de tecnologia foram envolvidas nos projetos de pesquisa dos ambientes de trabalho e no planejamento de campanhas, além de contribuírem para os seminários da rede dirigidos aos instrutores de transferência.

\section{Síntese do Caso 1}

Essa rede foi desenvolvida em torno de uma agenda comum, de um novo storyline, que estabeleceu um entendimento específico quanto ao caráter dos problemas ergonômicos e de como eles deveriam ser resolvidos. Esse storyline representa uma solução para o dilema entre cuidar de um cliente e reduzir o grande esforço físico do cuidador. Além disso, ele atendeu aos aspectos sócio-técnicos do problema, percebendo-o como uma questão de mudança organizacional e introduzindo um novo grupo de atores - os instrutores de transferência - como agentes de mudança. Dessa forma, a rede realmente contribuiu para a renovação da governança nesse campo.

A rede incluiu de fato entidades muito diferentes: instituições de pesquisa, consultores, agentes sociais do mercado de trabalho e firmas particulares. Algumas delas pertenciam ao campo político da SST, outras ao campo da política social. Além disso, os terapeutas, enquanto grupo profissional, trouxeram consigo uma visão de trabalho centrada nos clientes e desempenharam importante papel em diferentes partes da rede. A heterogeneidade da rede foi, claramente, importante fonte de capacidade inovadora e contribuiu para consolidar o conceito.

A rede cresceu de baixo para cima, significando que os membros tiveram de criar as arenas e os recursos necessários para seu desenvolvimento e sua manutenção. Os projetos desempenharam um importante papel como arena para interação e como um canal distributivo de recursos em termos de tempo e de economia.

Contudo, outras arenas desenvolveram-se também. Uma delas foi o seminário anual para instrutores de transferência, da mesma forma que reuniões regulares entre as instituições foram também estabelecidas. Desse modo, a capacidade política entre os atores foi desenvolvida. Eles puderam realmente se ver como atores que desempenharam papel significativo na governabilidade desse campo específico e desenvolveram experiência com diferentes formas de ação política. O estabelecimento de financiamento público foi crucial como condição para desenvolver e manter a rede. Mas isso também foi, evidentemente, uma fonte de instabilidade, pelo fato do financiamento ser precário. A rede foi, portanto, em si mesma, uma espécie de projeto que teve de ser renovado constantemente.

\section{Caso 2. Promoção da Saúde no Local de Trabalho (PSLT) $^{13}$}

\section{Contextualização}

Nos anos 1990, a desigualdade em saúde foi crucial para alavancar o debate em saúde e em promoção da saúde na Dinamarca. Apontava-se, repetidamente, que a mortalidade de homens com baixa qualificação profissional era $50 \%$ mais alta do que a mortalidade de homens com educação mais elevada, da mesma forma que a saúde, em geral, era desigualmente distribuída entre pessoas pertencentes a diferentes classes sociais. Como de modo geral se reconhecia que as campanhas de promoção da saúde falhavam em influenciar o comportamento dos grupos-alvo mais necessitados, a Promoção da Saúde nos Locais de Trabalho (PSLT) foi incluída na agenda. O local de trabalho foi visto como arena para tornar mais saudável a vida dos indivíduos de classes sociais de menor poder aquisitivo. De outro lado, o ambiente de trabalho também contribuiu para explicar a desigualdade em saúde, de modo que o ambiente de trabalho também deveria ser melhorado.

Neste estudo de caso, ilustramos como uma rede, que consiste de atores do campo da saúde e do campo da SST, estabeleceu um novo storyline para a saúde no trabalho, fundando um conceito integrado para a Promoção da Saúde nos Locais de Trabalho. Em resumo: "A promoção da saúde diz respeito tanto à melhoria do ambiente de trabalho, como a criar condições que favoreçam escolhas saudáveis dentro e fora do trabalho" (ARBEJDSTILSYNET, 2001). O estudo de caso está baseado em entrevistas qualitativas e estudos de documentos. Foram conduzidas oito entrevistas semi-estruturadas, com pessoas que desempenham papel-chave no processo. Além disso, também foi realizada uma análise de documentos essenciais, tais como trabalhos relacionados a essa política, planos de ação, manuais de orientações e relatórios.

\section{Desafios à regulação tradicional}

A perspectiva dominante na regulação da SST apóia-se geralmente em abordagens coletivas. O foco recai sobre as condições de trabalho comuns mais do que no comportamento individual ou nas precondições. Isto é particularmente verdadeiro na Dinamarca, onde os atores como a Inspetoria do Trabalho e os servi-

${ }^{13}$ Nota do Tradutor: estamos traduzindo 'Workplace Health Promotion: WHP’ por 'Promoção da Saúde nos Locais de Trabalho: PSLT'. 
ços de saúde ocupacional foram primordialmente orientados no sentido da prevenção organizacional e técnica mais do que na prevenção médica. O foco principal é o ambiente de trabalho e por anos, o 'slogan' foi: "O ambiente de trabalho é que é o paciente, não o trabalhador". Além disso, a distinção entre seres humanos no trabalho e na vida privada é uma delimitação importante do campo. Conseqüentemente, a introdução da PSLT realmente desafia de diversas maneiras a regulação em SST, na forma como a conhecemos.

De outro lado, a PSLT pode também potencializar a renovação do campo da SST. Esse campo está experimentando uma espécie de crise, pois a abordagem tradicional parece ser inadequada na formulação de conceitos importantes acerca dos problemas da vida do trabalho moderno, como os problemas relacionados ao estresse e aos distúrbios músculo-esqueléticos. Esses problemas são caracterizados por sua alta complexidade e não podem ser explicados apropriadamente pelo reconhecimento unidimensional de fatores relacionados à carga de trabalho no ambiente de trabalho. Portanto, assiste-se a uma tendência: mais problemas relacionados ao local de trabalho têm sido administrados dentro do campo dos Recursos Humanos do que no campo da SST. A questão é, portanto, se a abordagem mais individualista da Promoção da Saúde no Local de Trabalho pode ser utilizada na renovação do campo da SST sem solapar os entendimentos e posições já adquiridos.

Esses dilemas estão no cerne da questão, quando atores de ambos os campos se engajam na construção de uma rede com o storyline voltado à PSLT. Os processos na rede são melhor caracterizados como sendo cuidadosamente negociados e balanceados, tentando renovar, embora preservando as antigas aquisições.

\section{Novo storyline - integração do estilo de vida com o ambiente de trabalho}

Durante o período de 1998 a 2004, estabeleceu-se um novo storyline em PSLT. Esse processo foi estimulado pelo trabalho de uma comissão de saúde pública, que lançou um relatório e recomendações, em 1999. O storyline da PSLT está mais claramente resumido na seguinte citação:

"O local de trabalho pode ter grande influência sobre a saúde dos empregados. A vida no trabalho pode aumentar os recursos e o bem estar dos empregados ou conduzi-los a condições psíquicas e físicas inadequadas, por causa de um ambiente de trabalho ruim. O local de trabalho também contribui para estabelecer normas e hábitos em relação à saúde. Assim, a Promoção da Saúde no Local de Trabalho diz respeito tanto a melhorar o ambiente de trabalho quanto a proporcionar contexto que facilite escolhas saudáveis no trabalho e fora dele." (ARBEJDSTILSYNET, 2002, p. 5)
Essas formulações relativamente amplas implicam que a perspectiva coletiva da SST e a perspectiva do estilo de vida individual deveriam ser aplicadas simultaneamente. Acima de tudo, isso está baseado numa compreensão de que o ambiente de trabalho e o estilo de vida interagem de forma complexa. O estilo de vida não é somente uma questão de escolhas individuais; o trabalho e outros fatores interferem; mas, de outro lado, as escolhas individuais também não podem ser desrespeitadas. Como afirmou uma das pessoas-chaves entrevistadas ${ }^{14}$ :

"O indivíduo é responsável pela sua própria saúde, não importa qual seja seu local de trabalho e não importa que tipo de vida você viva. Mas, quando você fala sobre o local de trabalho, então esse local de trabalho tem a responsabilidade de criar um sistema saudável e um bom ambiente de trabalho".

O storyline é ambíguo em diferentes aspectos; também quando chega a conceitos mais fundamentais de saúde e de promoção da saúde. Olhando para as interpretações e práticas que são desenvolvidas, algumas estão baseadas em entendimentos médicos, nas quais a PSLT está basicamente relacionada à redução de doenças entre os empregados, primordialmente por métodos dirigidos por especialistas. Outras inclinam-se sobre concepções humanistas de saúde e de promoção da saúde, inspiradas por Antonovsky (1987), que objetivam o empoderamento dos empregados para que possam dominar, por si próprios, os agentes causadores das tensões que encontram.

\section{Construindo a Rede e suas Políticas}

Duas instituições tornaram-se essenciais para o processo concomitante de construir uma rede e de desenvolver o novo storyline:

- "Comitê para a PSLT", sub-comitê dentro do Conselho Nacional para o Ambiente de Trabalho (que presta contas diretamente ao Ministro do Trabalho) - O comitê para a PSLT tinha a tarefa de desenvolver um conceito integrado de SST e de PSLT e métodos para integrar a PSLT num trabalho seguro no local de trabalho. Esse comitê era presidido por um representante do Ministério da Saúde e possuía como membros representantes da Inspetoria do Trabalho e dos principais agentes sociais do mercado de trabalho. Esse comitê é em si próprio um ator, mas também constitui uma arena em que outros atores estratégicos podem ter acesso.

- "Centro Nacional para a Promoção da Saúde do Local de Trabalho - CNPSLT"15, fundado pelo Ministério da Saúde, tem como objetivo a propagação de conhecimentos, experiências e

\footnotetext{
${ }^{14}$ Æbelø,K. Gerente do Centro Nacional para a Promoção da Saúde no Local de Trabalho (entrevistado em 2006).

${ }^{15}$ Nota do Tradutor: em inglês, 'National Centre for Workplace Health Promotion'.

${ }^{16}$ Nota do Tradutor: no original, em inglês, os autores denominaram essa rede de 'Healthy City Network'.
} 
métodos, além do desenvolvimento de competências e redes profissionais. O CNPSLT se origina da "Rede de Cidades Saudáveis"16 - uma cooperação existente entre algumas das grandes cidades da Dinamarca -, principalmente pelos profissionais que foram pioneiros em trabalhar com a PSLT desde meados da década de 1990. O CNPSLT foi um importante ator no desenvolvimento desse storyline, mas ao longo de suas atividades criou também outras redes de profissionais.

Abaixo, a partir de alguns atores, descrevemos, sumariamente, a abordagem e interpretação de cada um desses para a PSLT e a contribuição específica desses atores para a rede.

\section{A Inspetoria do Trabalho}

O programa governamental em saúde pública, que visou aumentar o tempo de vida média dos dinamarqueses, incumbiu a Inspetoria do Trabalho (formalmente, a Autoridade Dinamarquesa responsável pelos Ambientes de Trabalho) a tomar iniciativas. A Inspetoria do trabalho tradicionalmente reconhecia o ambiente de trabalho como o núcleo da questão. Dar atenção a outros fatores que poderiam afetar a saúde não era de sua competência e dar atenção a esses outros fatores poderia também solapar a prioridade do ambiente de trabalho. Entretanto, o engajamento na rede mudou esse entendimento, pelo menos parcialmente. Eles se distanciaram desse tipo de visão, de "um olho só", e enfatizaram como o ambiente de trabalho é, em realidade, parte de uma agenda importante na melhoria da saúde dos empregados. Sua concepção de saúde é preferencialmente convencional (médica), mas - mantendo sua abordagem coletiva - eles apontam os fóruns baseados na representação coletiva das partes, como comitês por local de trabalho e comitês de segurança, como os meios mais apropriados para ancorar os projetos de PSLT em âmbito local.

A PSLT está incorporada em duas campanhas principais da Inspetoria do Trabalho: no setor administrativo e no setor industrial. Os inspetores de trabalho foram treinados para incorporar, em conjunto com a realização das fiscalizações das campanhas, estímulos para que as empresas fizessem algo pela PSLT. Outro modo pelo qual a PSLT foi promovida se deu nas certificações voluntárias de ambiente de trabalho, que as empresas, de acordo com a última reforma (2004) da legislação dinamarquesa, foram encorajadas a obter. Para adquirir uma certificação, as empresas têm de decidir de que forma vão encarar a promoção da saúde. A promoção da saúde é vista como algo além das exigências legais da Lei do Ambiente de Trabalho, algo extra, tanto em relação aos certificados, quanto na agenda da Inspetoria do Trabalho.

A Inspetoria do Trabalho torna-se um ator estratégico na rede devido a seus recursos e sua legitimidade no campo da SST. Ela distribui recursos econômicos para os projetos locais de melhor prática em PSLT e publicam livretos, manuais de orientações e outros materiais, além de estabelecer sanções legais.

Os sindicatos dos trabalhadores e as organizações dos empregadores

Os sindicatos dos trabalhadores também estiveram dentre os principais condutores da rede. Ao mesmo tempo, foram os que demonstraram a maior ambigüidade ao se engajarem na PSLT. Como sindicatos, estão comprometidos com a agenda coletiva e não se sentem à vontade para interferir nas escolhas individuais de seus afiliados. Contudo, como representantes dos grupos que são prejudicados pela desigual distribuição de saúde, são altamente motivados para entrar no processo em que o conceito de PSLT é formatado. Como uma das pessoas-chave da Confederação dos Sindicatos Dinamarqueses (LO) expressou:

"A desigualdade social em saúde nos trouxe para dentro. Nós devemos combatê-la. Alguns dos colegas no movimento começaram a dizer, 'nós não podemos continuar fechando nossos olhos; isto é algo em que devemos prestar atenção"”.

A integração da SST com o estilo de vida promete um caminho para contornar alguns desses dilemas. Mas é também entre os Sindicatos que as concepções humanistas sobre as atividades de promoção da saúde são mais claramente desenvolvidas, como está expresso com clareza numa citação extraída do livreto dos Sindicatos em PSLT:

Nós acreditamos que a saúde é também uma questão de estar no controle - influência real sobre sua própria vida e suas próprias escolhas. Um bom trabalho é um trabalho com responsabilidade, porque a responsabilidade dá ao indivíduo o "status" de ser uma parte importante da comunidade (LO, 2001, p. 10).

Desse modo, a PSLT está ligada às discussões em andamento sobre democracia, desenvolvimento e empoderamento na vida do trabalho. Assim, os sindicatos apóiam veementemente o desenvolvimento de projetos de PSLT baseados na aprendizagem e na participação dos empregados.

Já para os empregadores, sua agenda assume primordialmente que a PSLT não deve ser posta como uma demanda pelas autoridades. Os projetos de PSLT são melhor executados por empresas, individualmente, em bases voluntárias. Isso as coloca num papel passivo, mas benevolente, na rede, onde utilizam mais ou menos a mesma abordagem que a Inspetoria do Trabalho, com respeito à PSLT: a tarefa é reduzir as enfermidades individuais, mas essa tarefa deve estar ancorada nas instituições coletivas do local de trabalho.

\section{O Centro Nacional para a Promoção da Saúde no Local} de Trabalho-CNPSLT

O CNPSLT nasceu, como mencionado anteriormente, da iniciativa "Cidade Saudável” e pertence, na polí- 
tica, ao campo da saúde. O centro tem uma história de trabalho com a PSLT desde o início da década de 1990. O centro está constituído, sobretudo, de profissionais de saúde, tais como fisioterapeutas e terapeutas ocupacionais. Sua abordagem para a PSLT foi holística e enfatizou potencialidades para o desenvolvimento e aprendizagem, tanto no nível individual como organizacional e, dessa forma, foi primordialmente inspirado por abordagens humanistas da PSLT.

A meta do CNPSLT era coletar, desenvolver e disseminar conhecimento, experiência e métodos; organizar, criar e manter redes profissionais no campo. Esse centro nacional foi bastante ativo e esteve envolvido em diversas atividades importantes como: atividades educativas dirigidas a diversos grupos profissionais e criação de redes de trabalho para esses mesmos grupos; participação em muitos dos principais projetos de pesquisa e de intervenção na área; atuação nos desdobramentos das iniciativas da Inspetoria do Trabalho. Eles desempenharam um papel muito importante na rede, pois desenvolveram as “melhores práticas", conceitos e métodos - elementos que são inevitáveis para a institucionalização do storyline. Seu conceito mais importante - o perfil de saúde pessoal e dolocal de trabalho-foirealmente exitoso ao construir um duplo-foco, tanto em relação ao indivíduo como ao local de trabalho, efoi uma tentativa de resolver um dos principais dilemas de combinar estilo de vida com SST.

\section{Instituições de pesquisa}

Duas instituições contribuíram especialmente com dados estatísticos, que serviram de base para a hipótese de que a saúde pública é fortemente estratificada segundo a classe social: O Instituto Nacional para a Saúde Pública e o Instituto Nacional para a Saúde Ocupacional. O último utilizou os dados de uma pesquisa nacional de coorte sobre o ambiente de trabalho e produziu um relatório, cujo título se traduziu em "Estilo de vida - ambiente de trabalho na Dinamarca, 2000 (ALBERTSEN; BURR, 2001). Essa pesquisa foi bastante influente e afirmou, também, que o ambiente de trabalho era responsável por cerca de 50\% da desigualdade em saúde.

Um livreto publicado (quase) ao mesmo tempo enfatizou que a divisão tradicional entre ambiente de trabalho, saúde e estilo de vida constitui um problema:

É importante que essas tradições sejam quebradas, a fim de acelerar experiências de desenvolvimento de novos métodos nos locais de trabalho, de modo que a desigualdade social [em saúde] possa ser reduzida (ARBEJDSMILJØINSTITUTTET ${ }^{17}, 2000$, p. 11).
Assim, essa instituição de pesquisa realmente desempenhou importante papel em legitimar a abordagem integrada para a PSLT.

Contudo, essas pesquisas focalizavam principalmente as causas da desigualdade em saúde, ao passo que pesquisas em busca de soluções são escassas. O principal esforço de pesquisa relacionado com a promoção da saúde foi o Projeto "Ônibus Saudável"18 (POULSEN, 2004). Esse projeto era ambicioso e amplo, envolvendo muitas práticas de organização e de atividade política e dessa forma nunca se ajustou ao paradigma de pesquisa do Instituto Nacional, baseado em evidências empíricas. Depois que o projeto terminou em 2004, as atividades do instituto tornaram-se bastante limitadas; portanto, nenhuma evidência consistente sobre a efetividade da abordagem integrada para a PSLT em prol da melhoria da saúde das pessoas foi produzida. O que demonstra a fragilidade da institucionalização desse storyline.

\section{Instituições Profissionais}

Como foi descrito acima, o 'Centro Nacional para o PSLT' foi o ator que traduziu o storyline para a prática, desenvolvendo os "melhores casos", conceitos e métodos. Esses conceitos e a abordagem holística da PSLT foram difundidos através de uma rede mais livre, formada de instituições profissionais, principalmente para os serviços de saúde e segurança no trabalho. Quase a totalidade do sistema de serviços de SST recebeu a PSLT como um item 'pronto para uso'19; partes do sistema vendem exames de saúde também e outros se utilizam de modelos de perfis de saúde pessoal e do local de trabalho; esses dois métodos são vistos usualmente como parte menor de uma intervenção mais ampla, por exemplo, com a finalidade de introduzir uma política de saúde no local de trabalho. Outros tipos de grandes companhias de consultoria também estão ativas no mercado. Contudo, a integração dessas instituições profissionais na rede realmente começou bastante tarde (por volta de 2002) na vida muito curta da rede. Como os serviços de saúde em SST estão privatizados e dramaticamente reestruturados desde 2004, a disseminação do storyline, que poderia ser feita potencialmente por parte desse atores da rede, não foi realizada.

Veladamente, outro tipo de fornecedores tem crescido: companhias pequenas de 1 a 2 pessoas que vendem produtos restritos como cursos para "parar de fumar" e que estabelecem e mantém pequeno escritório de trabalho em sala distante da companhia compradora etc. Elas não aplicam o conceito integrado para o

\footnotetext{
${ }^{17}$ Instituto Nacional para a Saúde Ocupacional.

${ }^{18}$ Nota do Tradutor: no original, em inglês, os autores denominaram esse projeto como 'Healthy Bus Project'

${ }^{19}$ Nota do Tradutor: no original, em inglês, os autores utilizam o termo 'off-the-shelf'.
} 
PSLT, mas uma abordagem restrita para o comportamento individual em saúde.

\section{Ascensão e queda?}

Desde 2004, diversos dos atores estratégicos no campo dinamarquês da PSLT perderam suas posições: o Centro Nacional para a PSLT foi desmantelado e as atividades que ainda continuam estão de volta às organizações locais do "Cidade Saudável", de onde vieram. A Inspetoria do Trabalho, depois de uma mudança de governo, direcionou seu interesse novamente para suas "tarefas nucleares": fiscalizar o ambiente de trabalho. No momento, o Instituto Nacional de Saúde Ocupacional presta limitada atenção à PSLT em sua pesquisa e o comitê de PSLT, dentro do Conselho Nacional de Ambiente de Trabalho, foi "reestruturado" para que perdesse suas funções. Isso significa que o conceito integrado de PSLT perdeu sua posição dominante: ele ainda existe, mas recuou para segundo plano.

Ao mesmo tempo, os consultores, de modo geral, têm muitos produtos nas prateleiras e as demandas dos clientes por esses produtos parecem não estar desaparecendo. O "marketing” da PSLT está tomando a dianteira. A PSLT torna-se parte do Gerenciamento de Recursos Humanos e freqüentemente serve como benefício marginal nas maiores empresas. O resultado em relação à saúde é desconhecido, mas o que é certo é que o problema da desigualdade em saúde não está abordado.

\section{Síntese do Caso 2}

A rede descrita aqui foi desenvolvida em torno de uma agenda comum, um novo storyline que estabeleceu uma compreensão específica da PSLT: de quais problemas a PSLT deveria tratar, como e por quem. O storyline transmite um entendimento da PSLT que, de um lado renova o campo da SST ao introduzir a perspectiva individual, de outro, mantém o foco sobre um ambiente coletivo e aponta fóruns coletivos como principais incentivadores do PSLT. O storyline representa uma solução para os dilemas de como combinar dois campos que diferem radicalmente em sua abordagem da saúde - o campo da promoção da saúde e o campo da SST. A promoção da saúde vem do setor da saúde, e é vista ali como um dos modos de trabalhar de forma profilática e de implementar a estratégia da Organização Mundial de Saúde (OMS): "Saúde para todos". O conceito de PSLT era quase vazio a princípio. Ele precisava ser preenchido com conteúdo. Se fosse apenas fumar, beber, comer e fazer exercícios, seria promoção da saúde; mas quando combinado com bem estar, estresse ou posturas de trabalho, torna-se significativo para o contexto do trabalho. Ao prover ferramentas a serem usadas no processo, torna-se trabalhável, assim como, ao produzir identidades profissionais - através da capacitação dos inspetores do trabalho ou dos con- sultores de saúde -, conquista a necessária força de trabalho. Além disso, através da pesquisa e de outras formas de produção de conhecimentos, adquire a necessária legitimidade.

A rede incluiu entidades particularmente diferentes: autoridades, agentes sociais do mercado de trabalho, instituições de pesquisa, profissionais de SST e de instituições especializadas como o Centro Nacional para o PSLT. A maioria delas, porém, pertencia ao campo da política de SST; somente o Centro Nacional para a PSLT possuía clara afinidade com o campo da saúde. Entretanto, os terapeutas, como um grupo profissional, que aparece tanto nos Serviços de SST como no Centro Nacional para a PSLT, também desempenham um papel na aproximação das duas abordagens para a saúde, as individualistas e as centradas nos ambientes de trabalho. A heterogeneidade da rede é uma fonte importante de capacidade inovadora.

A rede é essencialmente estabelecida de cima para baixo, ou especificamente, as duas entidades que constituem os atores estratégicos mais importantes são estabelecidas pelos respectivos ministérios. Isso implica que recursos do Estado, em termos de tempo, de economia e de conhecimentos, foram postos à disposição para a tarefa específica de estabelecer uma abordagem integrada da PSLT; e esses recursos foram a base para o desenvolvimento de conceitos, métodos e "melhores práticas' e para difundi-los através de cursos, seminários, panfletos, revistas etc. Desse modo, outros atores são recrutados para a rede, primordialmente a partir dos Serviços de SST, mas também de outras consultorias privadas. O storyline é consolidado de diferentes modos. Com a Inspetoria do Trabalho como um ator proeminente na rede, o conceito "integrado" da PSLT foi incorporado à estrutura legal de trabalho (embora com prudência). Também as atividades de treinamento do Centro Nacional para a PSLT serviram para institucionalizar o conceito integrado. As instituições de pesquisa estiveram, contudo, ausentes quando chegou o momento de avaliar as abordagens que foram geradas. Mas, no todo, a capacidade e a identidade política entre os atores foram desenvolvidas. Eles realmente se viram como atores que se movimentaram para além de velhos preconceitos e que agora desempenhavam um papel construtivo e importante ao propagarem uma nova abordagem para a saúde no trabalho.

Como se verificou ao final, o storyline foi frágil. Uma causa disso foi que a rede que apoiava o storyline foi desmantelada. A rede foi estabelecida a partir de cima e quando o incentivo vindo de cima se esgotou, a institucionalização do conceito integrado de PSLT foi paralisada, antes que ganhasse força. Outro fator que apontamos é que a ponte integradora entre a SST e o estilo de vida, depois de tudo, não era suficientemente forte, sobretudo porque somente poucos atores do campo da saúde foram incluídos na rede. Isso foi fatal, porque o campo da saúde, como campo político, é muito mais forte do que o campo da SST. 


\section{Considerações finais e perspectivas}

\section{Eliminando controvérsias entre diferentes campos}

Os dois casos ilustram de que modo a governança em rede trabalha como um mecanismo para eliminar controvérsias entre campos que diferem em suas visões sobre os problemas e sobre as soluções. No primeiro caso, vemos como a regulação do trabalho dos cuidadores é capturada pela concepção industrial, a respeito do ambiente de trabalho e do trabalho propriamente dito, implicando que este seja percebido como árduo. Introduzir instituições e profissionais centrados nos clientes e enraizados no campo da política social cria uma ponte entre os dois mundos e conduz a uma ênfase sobre os aspectos relacionais do trabalho e assim também uma concepção de trabalho como uma atividade significativa. O segundo caso pertence a uma agenda mais ampla. Ele trata da renovação da regulação em SST num contexto em que os problemas parecem ainda mais complexos e em que a individualização colore concepções de ambos os problemas e soluções. Interligar a SST com a Promoção da Saúde num conceito de "Promoção da Saúde no Local de Trabalho” poderia parecer muito difícil à primeira vista: uma tentativa de colocar uma "ponte" para superar uma distância grande demais. Mas o campo é ainda jovem e a arena está preparada para outra rodada. Significa tentar manter o foco sobre causas coletivas (as organizacionais e as tecnológicas) de um lado, e do outro, incluir precondições e problemas individuais relativos à saúde e à vida social.

\section{O Estado como meta-governador}

Em ambos os casos, o Estado forneceu à rede atores estratégicos, que possuem legitimidade e recursos econômicos. No primeiro caso, as autoridades são incluídas apenas fragilmente na rede. Contudo, seu papel como uma espécie de meta-governador não deve ser subestimado. O estabelecimento do financiamento público é crucial como uma condição para desenvolver e manter a rede. E mais tarde, no processo de desenvolvimento, as autoridades também incluem o sistema de instrução de transferência em seus manuais de orientações.

No segundo caso, os dois programas governamentais de saúde pública deram atenção ao local de trabalho como uma arena para as questões de saúde. Essa foi a base sobre a qual foi possível para o Ministério da Saúde financiar o CNPSLT e sobre a qual a Inspetoria do Trabalho se envolveu no assunto e superou parte da resistência advinda dos agentes sociais do mercado de trabalho. A Inspetoria do Trabalho foi encarregada de cuidar de uma parte do orçamento para financiar alguns projetos (em 2001). O Instituto Nacional de Saúde Ocupacional também recebeu fundos para fazer pesquisas no campo. O Estado não somente desempenhou um papel, mas funcionou como produtor das atividades conjuntas dos diversos atores. Embora não tenha estabelecido uma estratégia bem organizada e coerente, o Estado gerenciou o apoio à rede que, de outro modo, nunca teria se tornado real.

\section{Redes, regulação branda ou simplesmente desregulação?}

O resultado desses casos de governança em rede é uma espécie de "regulação branda". Esses casos ilustram algumas das qualidades positivas dessa espécie de regulação, tais como sua flexibilidade e habilidade para tratar de problemas complexos. O conceito de instrução de transferência que foi desenvolvido é notável, porque criou novos atores no campo do ambiente de trabalho, os instrutores de transferência, aos quais se buscou favorecer e dar poder para agir como agentes de mudanças. Os instrutores de transferência poderiam ser representantes da segurança e, em alguns casos, eles realmente são. Mas, em muitos casos, os instrutores de transferência são concebidos como um "recurso extra", quando uma pessoa externa à organização de segurança é escolhida.

Os aspectos negativos da 'regulação branda' - desregulação -, contudo, também se aplicam a esses casos. A pergunta é: até que ponto os instrutores de transferência, apoiados por consultores e diversas atividades iniciadas pela rede, são de fato capazes de lidar com os problemas complexos que, se supõe, lhes cabe tratar? Este sistema de instrutores é uma desculpa para não intervir no setor e, assim, não resolver os graves problemas de saúde dos cuidadores? Os estudos de avaliação sobre o sistema de instrutor de transferência, de fato, não são claros quando pretendem verificar os resultados desta experiência: os problemas de saúde não foram resolvidos, embora as lombalgias e distúrbios não tenham aumentado nos últimos anos.

Considerando a promoção da saúde no local de trabalho (PSLT) como a integração de fato entre as preocupações com a saúde e com o ambiente de trabalho, para a qual, insistimos, ainda necessitamos de um maior desenvolvimento em termos de conceitos, ferramentas e exemplos para ser verdadeiramente efetiva, pode, se não for bem sucedida, ser percebida como forma de desregulação. O foco é movido dos fatores de saúde do trabalho para áreas individuais de responsabilidade; e as experiências ligadas ao local de trabalho apenas suportam tal mudança. A saúde é "produzida" tanto no trabalho como através do modo como as pessoas "comem e bebem"; uma não elimina a outra: a promoção da saúde no ambiente de trabalho ainda corre o risco de fazer isso.

Esses elementos sublinham, a nosso ver, a necessidade de interação entre a governança tradicional e a governança em rede. A capacidade inovadora da governança em rede é óbvia, mas se as autoridades não tomarem parte ativa na rede, os resultados podem ser insuficientes. 


\section{Referências}

ALBERTSEN, K.; BURR, H. Livsstil. Arbejdsmiljø i Danmark 2000. København: Arbejdsmiljøinstituttet, 2001.

ANDERSEN, V.; BJURVALD, M. Vägar till färre arbetsskador - utveckling av nordisk ergonomitillsyn, modeller för ergonomisk riskvärdering. TemaNord, 1994, 514. Del 1.

. Vägar till färre arbetsskador - utveckling av nordisk ergonomitillsyn, tillsynsmetoder och kompetens. TemaNord, 1997, 516. Del 2.

ANTONOVSKY, A. Unravelling the mystery of health: how people manage stress and stay. San Francisco: Jossey-Bass Publishers, 1987.

ARBEJDSMILJØINSTITUTTET. Social ulighed i sundhed. Et bedre arbejdsliv. København, Arbejdsmiljøinstituttet, 2000.

ARBEJDSTILSYNET. Sunde kontorer - arbejdsmiljø og livsstil. København: Netværket og Nationalt Center for Sundhedsfremme på Arbejdspladsen, 2001.

. Sundhedsfremme på arbejdspladsen: vejledning om virksomhedernes arbejde med sundhedsfremme med henblik på at erhverve arbejdsmiljøcertifikat. København: Arbejdstilsynet, 2002. (At-vejledning F.5.2).

DONBÆK, L.; SCHIBYE, B. Personhåndtering - arbejdsmiljø og helbred. København: Arbejdsmiljøfondet, 1998.

ESKELINEN, L.; HANSEN, E. B. Indførelse og forankring af projekter til at forebygge bevægeapparatskader ved tunge personløft. København: AKF forlaget, 2004.

FRICK, K.; WREN, J. Reviewing occupational health and safety management: multiple roots, diverse perspectives and ambiguous outcomes. In: FRICK, K. et al. (Ed.). Systematic occupational health and safety management: perspectives and international development, Amsterdan: Pergamon, 2000. p. 17-42.

HAJER, A. M. The politics of environmental discourse: ecological modernization and the policy process. Oxford: Claredon Press, 1995.

HAJER, A. M.; WAGENAAR, H. (Ed.). Deliberative policy analysis: understanding governance in the network society. New York: Cambridge University Press, 2003.

JAMES, P. Wellbeing at work: an issue whose legislative time has come? Policy and Practice in Health and Safety, Great Britain, v. 1, n. 2, p. 5-18, Jan. 2003.

JESSOP, B. Governance and metagovernance: on reflexivity, requisite variety, and requisite irony. 2006. Disponivel em: <http://www.languageandcapitalism. info/wp-content/uploads/2006/08/jessopgovernance. pdf $>$. Acesso em: 14 jul. 2008.
KICKERT, W. J. M.; KLIJN, E. H.; KOPPENJAN, J. F. M. (Ed.). Managing complex networks: strategies for the public sector. London: Sage, 1997.

KORREMANN, G. Arbejdsliv og personløft sikkerhedsarbejde i kampagneperspektiv. København: BAR SoSu og Arbejdsmiljøfondet, 1999.

LIMBORG, H. J. The professional working environment consultant - a new actor on the health and safety arena. Human Factors and Ergonomics in Manufacturing, United States, v. 11, n. 2, p. 159-172, 2001.

LINDBLOM, C. E. The science of muddling through. Public Administration Review, Washington, n. 19, v. 2, p. 79-88, 1959.

LO. Arbejdsmiljø og sundhedsfremme. København: LO, 2001.

LUNDE, P. H. Bevægelse og forflytning - i stedet for at løfte. København: Gad, 2001.

MARCH, J. G.; OLSEN, J. P. Organizational choice under ambiguity. In: MARCH, J. G.; OLSEN, J. P. (Ed.). Ambiguity and choice in organizations. Bergen: Universitetsforlaget, 1976. Democratic governance. New York: The Free Press, 1995.

MARCH, J.G.; SIMON, H. A. Organizations. New York: Wiley, 1958.

POULSEN, K. B. The healthy bus project in Denmark: need for an action potential assessment. Health Promotion International, England, v. 19, n. 2, p. 205213, June 2004.

RHODES, R. A. W. Governance and public administration. In: PIERRE, J. (Ed.). Debating governance: authority, steering and democracy. New York: Oxford University Press, 2000. p. 54-90.

SCOTT, W. R. Institutions and organizations: toward a theoretical synthesis. In: SCOTT, W. R. et al. Institutional environments and organizations: structural complexity and individualism. London: Sage, 1994. p.55-80.

SOCIOLOGISK ANALYSE. Handlingsplanen om personløft - perspektiver på organiseringen af indsatsen - en procesevaluering. Århus: Sociologisk Analyse, 2000.

SØRENSEN, E.; TORFING, J. Netværksstyring: fra government til governance. Frederiksberg: Roskilde Universitetsforlag, 2005.

SWEC. Report on transfer instructor systems in danish municipalities. Sector Working Environment Council (Social and Health Sector). 2004. Unpublished. 